\title{
Impact of Ambient Air Pollution and Meteorological Factors on Hospital Admission to the Cardiovascular System Disease on Ulaanbaatar City of Mongolia
}

\author{
Altangerel Enkhjargal1 ${ }^{*}$, Badrakh Burmaajav², Sambuu Tsegmed ${ }^{3}$, Batbaatar Suvd ${ }^{3}$, \\ Byambagar Norolkhoosuren ${ }^{4}$, Dorj Unurbat ${ }^{5}$, Jadamba Batbayar ${ }^{5}$ \\ ${ }^{1}$ Academy of Medical Professionals, Ulaanbaatar, Mongolia \\ ${ }^{2}$ Mongolian Academy of Medical Sciences, Ach Medical University, Ulaanbaatar, Mongolia \\ ${ }^{3}$ National Center for Public Health, Ulaanbaatar, Mongolia \\ ${ }^{4}$ National center for Health Development, Ulaanbaatar, Mongolia \\ ${ }^{5}$ National Center for Environmental Monitoring, Ulaanbaatar, Mongolia \\ Email: *ajargal8@gmail.com
}

How to cite this paper: Enkhjargal, A., Burmaajav, B., Tsegmed, S., Suvd, B., Norolkhoosuren, B., Unurbat, D. and Batbayar, J. (2020) Impact of Ambient Air Pollution and Meteorological Factors on Hospital Admission to the Cardiovascular System Disease on Ulaanbaatar City of Mongolia. Open Journal of Epidemiology, 10, 100-114. https://doi.org/10.4236/ojepi.2020.102009

Received: April 25, 2019

Accepted: April 4, 2020

Published: April 7, 2020

Copyright $\odot 2020$ by author(s) and Scientific Research Publishing Inc. This work is licensed under the Creative Commons Attribution International License (CC BY 4.0).

http://creativecommons.org/licenses/by/4.0/ (c) (i) Open Access

\begin{abstract}
Background: Mongolia is situated in northern Central Asia. Landlocked between China and Russia, it is a vast expanse of high attitude grassland steppe, desert, and mountain covering an area of 1,565,000 square kilometers. Air pollution is an increasingly series problem in Mongolia. Materials and Methods: This is a time-series cross over study. All health and air pollution data of 2008-2017 was used for this survey. Results: The mean level of $\mathrm{SO}_{2}$ during the cold season was $35.22 \mu \mathrm{g} / \mathrm{m}^{3}$ and during the warm season it was 4.65 $\mu \mathrm{g} / \mathrm{m}^{3} .24$ hours PM10 concentration, during the cold season daily average concentration was $226.77 \mu \mathrm{g} / \mathrm{m}^{3}$. The 8 hours average daily carbon monoxide concentration $\left(1352.85 \mu \mathrm{g} / \mathrm{m}^{3}\right.$ [95\% CI: 1313.07 - 1396.15]) was high during the cold season, ozone concentration $\left(39.10 \mu \mathrm{g} / \mathrm{m}^{3}\right.$ [95\% CI: $\left.\left.37.95-40.35\right]\right)$ was high during the warm season. Air quality depends on metrological parameters. All correlation was statistically significant during the whole year and cold season. In total, 288,832 people get admitted to the hospital due to cardiovascular system disease in Ulaanbaatar during the year of 2008-2017. In general, hospitalization is increasing year by year. Significant associations were found for $\mathrm{SO}_{2}$ with hypertensive diseases (I10 - I15), ischemic heart diseases (I20 - I25), cerebrovascular diseases (I60 - I69), diseases of pulmonary circulation and other forms of heart (I00 - I09, I26 - I52) in all lags. For $\mathrm{NO}_{2}$ was less associated with Ischemic heart diseases (I20 - I25) and diseases of pulmonary circulation and other forms of heart (I00 - I09, I26 - I52). For
\end{abstract}


both PM10 and PM2.5, every disease had observed significant RR in lag 0 - 3 . Significant associations were found for air pollutants such as PM10, PM2.5, $\mathrm{CO}, \mathrm{SO}_{2}$, and $\mathrm{O}_{3}$ in all lags had a statistically significant association with cold season's cardiovascular system disease admission. As expected during the warm season significant association was found only lag 1 with PM2.5 and lags $(0,1) \mathrm{CO}$ and $\mathrm{O}_{3}$. Conclusion: As expected this study demonstrated significant correlations between cardiovascular morbidity with PM2.5, PM10, $\mathrm{NO}_{2}$, $\mathrm{SO}_{2}, \mathrm{CO}, \mathrm{O}_{3}$, and some meteorological parameters.

\section{Keywords}

Air Pollution, Cardiovascular System Disease, Meteorological Factors, Ulaanbaatar

\section{Background}

Mongolia is situated in northern Central Asia. Landlocked between China and Russia, it is a vast expanse of high attitude grassland steppe, desert, and mountain covering an area of 1,565,000 square kilometers. Mongolia has a surface area of nearly 1.6 million square kilometers with the Gobi desert in the south part and mountainous regions in the north and west part. Mongolia has a cold and windy continental climate which is common in the highland area. By mean temperature, Ulaanbaatar is the coldest capital city in the world and an only capital city that has minus yearly average temperature. Mongolia has 4 seasons [1]. More than $40 \%$ of the total population of Mongolia lives in Ulaanbaatar. In 2018, over 184,000 households live in the ger areas of six central districts and about 3200 the entities operate with heating low-pressure steam boilers in the capital city. $80 \%$ of air pollution comes from these pollution sources. In fact, during the winter, Ulaanbaatar's air pollution is caused by households and low-pressure boilers burning raw coal in Ger district (80\%); motor vehicle (10\%); coal-fired power plants (6\%); and solid waste and soil degradation (4\%). Air pollution is an increasingly series problem in Mongolia [2].

The atmosphere is a mixture of a gaseous substance produced over the Earth's long history by biogenic, geogenic, and atmosphere processes. By definition, air pollution is a mixture of solid, liquid and gaseous substances as well as biological objects emitted to the atmosphere caused by natural and anthropogenic activities that have detrimental effects on the animals, human health and economics. Nowadays, the anthropogenic impact on the atmosphere has been increasing with the enormous growth of the human population, the use of mineral resources, and the advanced technology and continues to be significant [3]. Based on the study of the elemental analysis of the fine-sized particulate matters (PM2.5) in the air of Ulaanbaatar city [4] found the main factors of the air pollution came from topsoil, from the wood and coal burnt and the car exhaust. However, the analysis was done in only one sampling point, so the results were not enough to 
be considered as the main source of air pollution of the capital city. According to the study carried out by World Bank in 2011, most of the particulate matters in the air of Ulaanbaatar city were originated from natural sources. The stationary and mobile sources of air pollution have polluted the neighboring areas and also the smokes from the ger areas surrounding the city have moved from uptown to downtown through air flows of the mountains and the rivers during winter time and remained in the valley and became a cause of the cumulative air pollution [5].

According to the Emission Inventory Report, in 2016, transport is accountable for 2.2 percent of total emissions of $\mathrm{SO}_{2}, 21.5$ percent of total emissions of $\mathrm{NOx}, 1.1$ percent of PM10 and 43.6 percent of CO. While contributions to $\mathrm{SO}_{2}$ and $\mathrm{PM} 10$ emissions are negligible, contribution to total emissions of NOx and especially $\mathrm{CO}$ is estimated quite high. It has to be taken into account that only road transport has been considered and that the formation of the road dust has been estimated separately with the contribution of 10.4 percent to total PM10 emissions [6].

As of 2018, 384,944 of motor vehicles were registered in Ulaanbaatar city which was increased in number by 100,000 than that of last year and mostly in numbers of sedan cars. Of latter ones, $81 \%$ and $16 \%$ were over 10 -year-old and 4 to 9-year-old the secondhand cars, respectively. Consequently, the motor vehicles increasing year to year have got the flow and activity of traffic to slow down and caused more traffic jams. The emitted pollutants into the air from the secondhand cars used for a longer year are increasing, thus affect badly to the air quality of the capital city. In Ulaanbaatar registered about 40,000 vehicles in 2000 and the number rises 365.800 in 2018 and approximately 68 - 70 percent of them are second hand and imported. Also, the percentage of diesel motor vehicles is high among all motor vehicles [2].

Many families there live in gers, traditional Mongolian dwellings consisting of a wooden frame beneath several layers of wool felt. In the ger districts of Ulaanbaatar, cooking and heating energy is provided through indoor coal combustion in metal stoves with chimneys, and in wintertime, such stoves may be in use both day and night [7].

A main reason of deteriorating air quality of the capital city during winter time is smoke which released from the conventional ger stoves with capacity of up to $10 \mathrm{~kW}$ such as the traditional and the improved stoves, home-built furnaces, small-size heat only boilers used in the households in ger area as well as in the entities that yet connected to the central heating system. Of 180,541 of the ger stoves with a capacity of up to $10 \mathrm{~kW}$ counted in 2013 were 85,900 in gers, 91,449 in houses and 3192 in entities that yet connected to the central heating system. It was estimated that a household in ger area was burnt approximately 820,000 tons of raw coal a year [6].

In addition, many researchers noted that during the wintertime, inverse cyclone flows come to Mongolia from Central Asia, causing temperature inversion to form in the city's atmosphere. The meteorological agency concluded that the temperature inversion was 500 to 800 meters of depth and 5 to 170 units of intensity. Due to this temperature inversion, dispersion of air pollutants and sub- 
stances is slowed down and the smog over the city becomes stagnant. Ulaanbaatar is situated between 4 mountains. This geographical location and meteorological condition are contributing to the temperature inversion during the winter months. During the winter months, the Central Asian or the Siberian anticyclone is dominating in the whole country. Through this anticyclone, there is leading a weak wind speed and a cool temperature which are causal of inversion [8] [9]. These sources contribute to high levels of urban air pollution, particularly during periods of temperature inversions, which are observed in the winter months when coal and wood combustion is at peak levels. We aimed to conduct air pollution health impact assessment at UB city.

\section{Materials and Methods}

This is a time-series cross over study. All health and air pollution data of 2008-2017 was used for this assessment.

In Ulaanbaatar 15 air quality monitoring stations are measure air pollutant including PM2.5 $\mu \mathrm{g} / \mathrm{m}^{3}, \mathrm{PM} 10 \mathrm{mg} / \mathrm{m}^{3}, \mathrm{SO}_{2} \mathrm{mg} / \mathrm{m}^{3}, \mathrm{NO}_{2} \mathrm{mg} / \mathrm{m}^{3}, \mathrm{CO} \mathrm{mg} / \mathrm{m}^{3}, \mathrm{O}_{3}$ $\mathrm{mg} / \mathrm{m}^{3}$. As well from the meteorological factors were used max, min and average temperature, humidity and wind speed. We get data from all stations which measure those indicators. Health and air pollution data will be collected in a routine based on related agencies. In Ulaanbaatar, 15 air quality monitoring stations are operating and out of them 12 had an automatic operating system. Thus, we used those 12 station's data for analyses of this article. All stations monitoring above mentioned indictors' were measured every 15 - 20 minutes daily. There are located in multisite places over the Ulaanbaatar city based on mobile and static pollutant's sources. Calibration of equipment is squared in accordance with the national standard MNS-17025.

Health-related data were obtained from statistical offices of all 6 secondary level hospitals, and 3 tertiary level hospitals, and other all state hospitals impatient data of UB city. Those secondary data of hospital admission data of selected diseases are a daily-based recorded and we will collect those data of each target hospitals in 2008-2017. Cardiovascular disease diagnosed at the study hospitals based on the ICD-10 disease classification system.

Based on exposure-response functions from Ulaanbaatar and from the literature health impacts are derived using the equation below.

$$
E=((\mathrm{RR}-1) / \mathrm{RR}) * f_{p} * \mathrm{POP}
$$

where $E$ is the number of cases of each health endpoint attributed to air pollution ("excess cases"), RR is the relative risk of health effect between two levels of pollution (here the current level and a lower level obtained from an intervention or the lower threshold level), this is the current incidence rate of the health effect, and POP is the exposed population considered. In the following, we assume POP is the total population in Ulaanbaatar, which was 1.5 million in 2017. For hospital admissions, we replace $f_{p}^{\star}$ POP with the actual annual number of hospital admissions. 
$\mathrm{RR}$ is given by:

$$
\mathrm{RR}=\exp \left(\beta *\left(C-C_{t}\right)\right)
$$

where $\beta$ is the exposure-response coefficient, $C$ is the current pollution level and $C_{t}$ is the target pollution level obtained from an intervention or the assumed threshold value.

Data were analyzed by using the program STATA-12. For testing the differences of the results were used appropriate non-parametric tests were used Kruskal-Wallis one way analysis of variance and Mann-Whitney $U$ test as well. Furthermore, time series cross-over and correlation analyses will be used for evaluating the health effects of air pollutants. Also, ANOVA was used for the parametric test. Furthermore, multiple variables analyses and correlation analyses were used for evaluating the health effects of air pollutant and meteorological parameters. Kolmogorov-Smirnoff test has been used to check the normality distribution of data. Pearson's correlation coefficient also has been used. To evaluate the lag effect in detail, we computed 24-h means starting from various times: the 0-h lag starts from 00:00 hours on a corresponding day, the 6-h lag starts from 18:00 hours on the previous day, and the 12-h lag starts from 12:00 hours on the previous day, ..., and they last for $24 \mathrm{~h}$. The 6-, 12-, 18-, 72-h, 96-h lags were calculated and used to get the estimated effects. The 0 -h lag is the pollutant value on the same day, the $24-\mathrm{h}$ lag is the 1 -day lag value, the 48 -h lag is the 2-day lag value, etc. In order to allow for different lag structures for different causes of disease, the traditional method, and the linear regression analysis were supplied for model comparison. We compared the three time-series models for lags of $0,1,2$ and 3 days.

\section{Results}

\subsection{The Tendency of Ambient Air Pollution of Ulaanbaatar, 2008-2017}

\section{$\mathrm{SO}_{2}$ and $\mathrm{NO}_{2}$}

The mean level of $\mathrm{SO}_{2}$ during the cold season was $35.22 \mu \mathrm{g} / \mathrm{m}^{3}$ [95\% CI: 33.78

- 36.68] and during the warm season it was $4.65 \mu \mathrm{g} / \mathrm{m}^{3}$ [95\% CI: $4.43-4.86$ which is 7.57 times higher than the warm season. If compare those levels with national standard and WHO recommended level, 1.8 times high during the cold period of time and 4.3 times less during the warm season. The $8^{\text {th }}$ of February of 2016, the highest level of $\mathrm{SO}_{2}$ was observed at $210 \mu \mathrm{g} / \mathrm{m}^{3}$ and it is 10.5 times higher than the national standard and WHO recommended permissible level. According to the $\mathrm{NO}_{2}$ level, the daily mean was $45.39 \mu \mathrm{g} / \mathrm{m}^{3}$ [95\% CI: 44.56 46.19] which was $4.56 \mu \mathrm{g} / \mathrm{m}^{3}$ higher from the permissible level of national standard and WHO recommendation level. The highest level of $\mathrm{NO}_{2} 164 \mu \mathrm{g} / \mathrm{m}^{3}$ was observed on the $11^{\text {th }}$ December 2011. Also during the holiday $\left(45.85 \mu \mathrm{g} / \mathrm{m}^{3}[95 \%\right.$ CI: 44.92 - 46.83]) mean concentration of $\mathrm{NO}_{2}$ was significantly higher than the ordinary day mean concentration $\left(44.34 \mu \mathrm{g} / \mathrm{m}^{3}\right.$ [95\% CI: 42.93 - 45.73]). During the cold period $\left(52.95 \mu \mathrm{g} / \mathrm{m}^{3}\right.$ [95\% CI: 51.96 - 53.99]) of time mean concentra- 
tion of $\mathrm{NO}_{2}$ was 1.66 times higher than the warm season $\left(31.25 \mu \mathrm{g} / \mathrm{m}^{3}\right.$ [95\% CI: 30.60 - 31.89) and it was 1.13 times higher than the national standard permissible level and WHO recommended level.

\section{PM10 and PM2.5}

According to environmental monitoring, the most polluted air pollutants of Ulaanbaatar are PM10 and PM2.5 in Ulaanbaatar. In generally, 74.0\% of the ambient air of Ulaanbaatar city PM10 consists of particular matter less than 2.5. During the last year's, $90.0 \%$ of days of whole year PM2.5 level was exceeded from the national standard level and it was reached $95.8 \%$ during the cold season. If compare those with WHO recommended level, whole year 98.1\%, cold season $99.7 \%$, and warm season it was $95.1 \%$. In terms of PM10 level, $64.8 \%$ of days were exceeded from the national standard and $90.0 \%$ of them were exceeded from the WHO recommended level. The 24 hours average PM2.5 concentration of the cold season was $114.10 \mu \mathrm{g} / \mathrm{m}^{3}$ [95\% CI: $109.16-119.04$ ] which is higher than the warm season 3.9 times, 2.3 times higher than the national standard level and 8.6 times higher than the WHO recommended level. Regarding the 24 hours PM10 concentration, during the cold season daily average concentration was $226.77 \mu \mathrm{g} / \mathrm{m}^{3}$ [95\% CI: 218.30 - 235.25] which is 2.4 times higher than the warm season, 3.7 times higher than the national standard level and 9.1 times higher than the WHO recommended level. The highest level of PM10 $\left(2047 \mu \mathrm{g} / \mathrm{m}^{3}\right)$ was recorded in the $31^{\text {st }}$ of January between $2008-2017$ which is 20.5 times high than the national standard permissible level and 40.9 times higher than the WHO recommended level. Whereas, PM2.5 highest concentration $\left(1010 \mu \mathrm{g} / \mathrm{m}^{3}\right)$ was recorded on $24^{\text {th }}$ December 2010 which is 20.2 times high than the national standard permissible level and 40.4 times higher than the WHO recommended level.

\section{Carbon monoxide (CO) and Ground-level Ozone $\left(\mathrm{O}_{3}\right)$}

Monitoring of carbon monoxide (since January 2010) and ozone (since January 2012) are relatively new indicators of air quality monitoring in Mongolia. Those two pollutants are not exceeded the national standard permissible and WHO recommended level. The 8 hours average daily carbon monoxide concentration $\left(1352.85 \mu \mathrm{g} / \mathrm{m}^{3}\right.$ [95\% CI: 1313.07 - 1396.15]) was high during the cold season, ground level Ozone concentration $\left(39.10 \mu \mathrm{g} / \mathrm{m}^{3}\right.$ [95\% CI: 37.95 - 40.35]) was high during the warm season. Table 1 shows air pollutants and some meteorological factors by different seasons and dows of the day.

\subsection{Relationship between Meteorological Factors and the Air Quality in Ulaanbaatar}

Air quality depends on metrological parameters. We used wind speed, average, maximum, mean daily temperature, and relative humidity. All correlation was statistically significant during the whole year and cold season. The general tendency of the whole year, all air pollutants apart from ground level ozone had defined strong reversely correlated with all surveyed metrological factors except relative humidity. The relative humidity and ground-level ozone had mild direct 
Table 1. Some meteorological and air pollutant's daily mean level, Ulaanbaatar, 2008-2017.

\begin{tabular}{cccccc}
\hline \multirow{2}{*}{ Characteristic } & $\begin{array}{c}\text { Ordinary day } \\
\text { Mean, 95\% CI }\end{array}$ & $\begin{array}{c}\text { Holiday } \\
\text { Mean, 95\% CI }\end{array}$ & $\begin{array}{c}\text { Cold season } \\
\text { Mean, 95\% CI }\end{array}$ & $\begin{array}{c}\text { Warm season } \\
\text { Mean, 95\% CI }\end{array}$ & $\begin{array}{c}\text { Whole year } \\
\text { Mean, 95\% CI }\end{array}$ \\
\hline Ave tem & $1.17[0.48-1.84]$ & $0.70[-0.40-1.78]$ & $-7.21[-7.77-6.64]$ & $16.40[16.07-16.73]$ & $1.02[0.46-1.60]$ \\
Wind velocity & $2.14[2.09-2.19]$ & $2.12[2.04-2.19]$ & $1.89[1.84-1.94]$ & $2.59[2.53-2.66]$ & $2.14[2.09-2.18]$ \\
Min tem & $7.75[7.02-8.45]$ & $7.15[5.97-8.23]$ & $-0.82[-1.44-0.19]$ & $23.22[22.86-23.59]$ & $7.56[6.95-8.16]$ \\
Max tem & $-4.33[-5.00-3.67]$ & $-4.67[-5.71-3.63]$ & $-12.39[-12.91-11.85]$ & $10.43[10.11-10.76]$ & $-4.43[-4.97-3.87]$ \\
Humidity & $56.01[55.31-56.76]$ & $56.44[55.34-57.62]$ & $58.49[57.79-59.23]$ & $51.74[50.65-52.88]$ & $56.14[55.54-56.75]$ \\
SO2 & $24.55[23.27-25.89]$ & $24.56[22.60-26.70]$ & $35.22[33.78-36.68]$ & $4.65[4.43-4.86]$ & $24.56[23.42-25.68]$ \\
NO2 & $45.85[44.92-46.83]$ & $44.34[42.93-45.73]$ & $52.95[51.96-53.99]$ & $31.25[30.60-31.89]$ & $45.39[44.56-46.19]$ \\
PM10 & $182.59[175.16-190.02]$ & $183.05[172.21-193.88]$ & $226.77[218.30-235.25]$ & $95.01[91.84-98.19]$ & $182.73[176.60-188.86]$ \\
PM25 & $85.29[81.29-90.02]$ & $85.65[79.59-92.17]$ & $114.10[109.16-119.04]$ & $29.21[28.01-30.40]$ & $85.72[82.14-89.31]$ \\
CO & $1058.42[1020.39-1101.08]$ & $1004.99[948.13-1066.72] 1352.85[1313.07-1396.15] 461.34[444.07-482.81] 1041.96[1010.88-1076.00]$ \\
O3 & $29.01[28.23-29.86]$ & $30.33[29.00-31.66]$ & $24.23[23.54-24.96]$ & $39.10[37.95-40.35]$ & $29.42[28.78-30.12]$ \\
\hline
\end{tabular}

with each other. During the cold season, a similar pattern was observed with a whole year correlation. However, correlation power little is decreased compared to the whole year pattern. Whereas during the warm season, significant correlations were defined as a reversely weak correlation between $\mathrm{CO}$ concentration with maxi temperature, average and maximum wind speed. $\mathrm{SO}_{2}$ concentration was directly weak correlated with average and minimum temperature and reversely weak correlated with maximum temperature, maximum and average wind speed. Also reversely mild correlated with relative humidity. Correlation pattern of ground-level ozone concentration with selected meteorological factors was the same as another season. $\mathrm{NO}_{2}, \mathrm{PM} 2.5$, and PM10 concentrations were directly weak correlated with average and minimum temperature, reversely weak (PM10 reversely mild) with relative humidity. Whereas, $\mathrm{NO}_{2}$ and PM2.5 concentrations were reversely weak correlated with average wind speed (Table 2).

\subsection{Tendency of Hospital Admission Due to Cardiovascular System Disease in 2008-2017 in Ulaanbaatar}

In total, 288,832 people get admitted to the hospital due to cardiovascular system disease in Ulaanbaatar during the year of 2008-2017. In general, hospitalization is increasing year by year the highest number of hospitalization due to cardiovascular system disease was registered in 2016.

The means of daily cardiovascular system disease admission, during weekdays, were 103.23 [95\% CI: 101.25 - 105.38], weekend it was 63.31 [CI\%: 61.02 65.75]. During the cold season (114.11 [95\% CI: 111.83 - 116.52]) on average, 8.79 person more admit to the hospital than the warm season due to CVD. From all cardiovascular system disease admission cases, the highest number of daily admission case was hypertensive diseases (I10 - I15) which daily mean level was 30.67 [95\% CI: 29.95 - 31.40]). According to the age group, $66.2 \%$ of patients 
Table 2. Matrix of Spearman's correlation coefficient $(r)$ between mean daily concentration of pollutants and meteorological data, Ulaanbaatar, 2008-2017.

\begin{tabular}{|c|c|c|c|c|c|c|}
\hline Indicators & $\mathrm{CO}$ & $\mathrm{O}_{3}$ & $\mathrm{SO}_{2}$ & $\mathrm{NO}_{2}$ & PM10 & PM25 \\
\hline \multicolumn{7}{|c|}{ Whole year } \\
\hline Average temperature & $-0.777^{\star \star}$ & $0.586^{\star *}$ & $-0.839^{\star \star}$ & $-0.556^{\star *}$ & $-0.579^{\star *}$ & $-0.754^{\star *}$ \\
\hline Min temperature & $-0.757^{\star \star}$ & $0.580^{* *}$ & $-0.813^{\star *}$ & $-0.534^{* *}$ & $-0.546^{* *}$ & $-0.728^{* *}$ \\
\hline Max temperature & $-0.789^{\star *}$ & $0.573^{\star *}$ & $-0.862^{\star \star}$ & $-0.576^{\star *}$ & $-0.610^{* *}$ & $-0.771^{\star *}$ \\
\hline Wind velocity & $-0.593^{\star *}$ & $0.482^{\star *}$ & $-0.581^{\star \star}$ & $-0.545^{\star \star}$ & $-0.429^{\star *}$ & $-0.510^{\star *}$ \\
\hline Wind max velocity & $-0.611^{\star *}$ & $0.587^{* *}$ & $-0.614^{\star *}$ & $-0.556^{\star *}$ & $-0.482^{\star *}$ & $-0.615^{\star \star}$ \\
\hline Humidity & $0.399^{* *}$ & $-0.468^{\star *}$ & $0.352^{\star *}$ & $0.284^{\star *}$ & $0.186^{\star \star}$ & $0.375^{\star \star}$ \\
\hline \multicolumn{7}{|c|}{ Cold season } \\
\hline Average temperature & $-0.713^{\star *}$ & $0.510^{\star *}$ & $-0.801^{\star *}$ & $-0.448^{\star *}$ & $-0.533^{\star *}$ & $-0.741^{\star *}$ \\
\hline Min temperature & $-0.676^{\star *}$ & $0.498^{* *}$ & $-0.771^{\star \star}$ & $-0.425^{\star \star}$ & $-0.498^{\star *}$ & $-0.706^{\star *}$ \\
\hline Max temperature & $-0.735^{\star \star}$ & $0.502^{\star *}$ & $-0.816^{\star *}$ & $-0.462^{\star *}$ & $-0.552^{\star *}$ & $-0.756^{\star *}$ \\
\hline Wind velocity & $-0.629^{\star *}$ & $0.507^{\star *}$ & $-0.614^{\star *}$ & $-0.545^{\star *}$ & $-0.454^{\star *}$ & $-0.589^{\star \star}$ \\
\hline Wind max velocity & $-0.676^{* *}$ & $0.621^{* *}$ & $-0.661^{\star *}$ & $-0.570^{* *}$ & $-0.534^{* *}$ & $-0.695^{* *}$ \\
\hline Humidity & $0.495^{\star *}$ & $-0.429^{* *}$ & $0.514^{\star *}$ & $0.359^{\star *}$ & $0.313^{\star *}$ & $0.509^{* *}$ \\
\hline \multicolumn{7}{|c|}{ Warm season } \\
\hline Average temperature & -0.047 & $0.446^{* *}$ & $0.121^{* *}$ & $0.072^{*}$ & $0.155^{* *}$ & $0.091^{\star *}$ \\
\hline Min temperature & -0.036 & $0.436^{\star *}$ & $0.217^{\star *}$ & $0.109^{\star *}$ & $0.246^{\star *}$ & $0.142^{* *}$ \\
\hline Max temperature & $-0.076^{*}$ & $0.362^{* *}$ & $-0.083^{\star *}$ & -0.026 & -0.033 & 0.006 \\
\hline Wind velocity & $-0.197^{\star *}$ & $0.156^{\star *}$ & $-0.193^{\star *}$ & $-0.240^{\star *}$ & -0.020 & $0.076^{\star}$ \\
\hline Wind max velocity & $-0.062^{\star}$ & $0.227^{\star *}$ & -0.048 & $-0.134^{\star *}$ & 0.016 & -0.016 \\
\hline Humidity & -0.044 & $-0.416^{* *}$ & $-0.428^{* *}$ & $-0.166^{\star *}$ & $-0.416^{* *}$ & $-0.159^{* *}$ \\
\hline
\end{tabular}

Correlation is significant at the 0.01 level (2-tailed). ${ }^{*}$ Correlation is significant at the 0.05 level (2-tailed).*

were aged 5 - 64 hospitalized due to CVD, $86.3 \%$ of patients aged over 65 were hospitalized due to CVD. The common hospital admitted disease of cardiovascular system disease was hypertensive (I10 - I15) (238,272, 44.1\%). The most common disease of the age group 5 - 64 was hypertensive diseases (I10 - I15) $(158,964,42.4 \%$. Hypertensive diseases (I10 - I15) (79,308, 48.2\%), and ischemic heart diseases (I20 - I25) (51,623, 31.3\%) were common causes of hospital admission due to cardiovascular system disease among people over 65 years old (Figure 1).

\subsection{Relationship between Meteorological Factors, the Air Quality and Cardiovascular System Disease Hospital Admission in Ulaanbaatar}

In this study, we estimated the correlation (Spearman's) between air pollutants, meteorological factors, and cardiovascular system disease admission. In the whole year, a reverse correlation was observed with average, maximum, minimum 


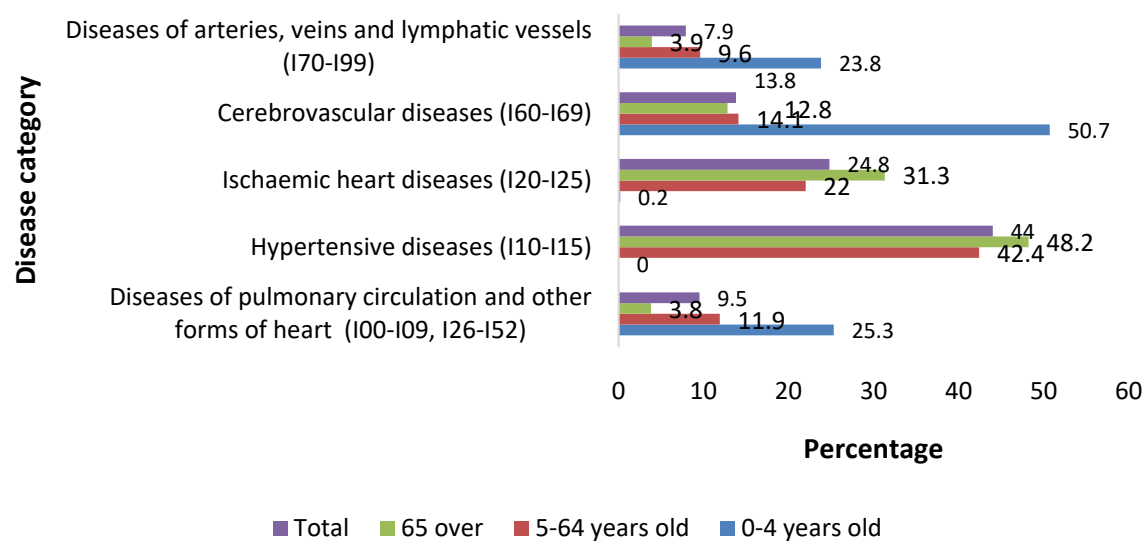

Figure 1. Hospital admission due to cardiovascular disease, by age group and disease category, Ulaanbaatar, 2008-2017.

temperature, and ozone. The direct correlation was observed with other parameters. This tendency was similar to the cold and warm season. However, during the cold season, the relationship was stronger than the warm season (Table 3).

\subsection{Time Series Analysis}

Significant associations were found for $\mathrm{SO}_{2}$ with hypertensive diseases (I10 I15), ischaemic heart diseases (I20 - I25), cerebrovascular diseases (I60 - I69), diseases of pulmonary circulation and other forms of heart (I00 - I09, I26 - I52) in all lags. For $\mathrm{NO}_{2}$ was less associated with Ischaemic heart diseases (I20 - I25) and diseases of pulmonary circulation and other forms of heart (I00 - I09, I26 I52). For both PM10 and PM2.5, every disease had observed significant RR in lag 0 - 3. Relatively weak RR with all diseases was defined for $\mathrm{O}_{3}$ and $\mathrm{CO}$ (Table 4).

Significant associations were found for air pollutants such as PM10, PM2.5, $\mathrm{CO}, \mathrm{SO}_{2}$, and $\mathrm{O}_{3}$ in all lags had a statistically significant association with cold season's CVD admission. As expected during the warm season significant association was found only lag 1 with PM2.5 and lags $(0,1) \mathrm{CO}$ and $\mathrm{O}_{3}$ (Table 5).

\section{Discussion and Conclusion}

According to this survey air pollution has been increasing intensively during the last decade in big cities of Mongolia especially in Ulaanbaatar due to urbanization, poor urban plan, migration from rural areas to urban areas, poverty, unemployment, economic crises, exercise with unclean technology mainly coal for heating and cooking, raise of number of motor vehicle and other air pollution sources; as a result of this phenomena population health has been worsening. Especially in winter time $\mathrm{SO}_{2}, \mathrm{PM} 10$ and PM2.5 concentrations are very high in ambient air because of raw coal usage in ger area around big cities such as Ulaanbaatar. Therefore, Ulaanbaatar is considered as the focus of air pollution. Overall, the single largest source of particulate pollution in Ulaanbaatar is coal combustion in households and low-pressure boilers, followed by power plants. 
Table 3. Matrix of Spearman's correlation coefficient $(r)$ between means a daily concentration of pollutants, meteorological data and mean daily admission of cardiovascular system disease, Ulaanbaatar, and 2008-2017.

\begin{tabular}{|c|c|c|c|c|c|}
\hline $\begin{array}{c}\text { Meteorological factors and } \\
\text { air pollutants }\end{array}$ & Ordinary day & Holiday & Cold season & Warm season & Whole year \\
\hline Ave tem, ${ }^{\circ} \mathrm{C}$ & $-0.096^{\star \star}$ & $-0.113^{\star \star}$ & 0.024 & $-0.081^{*}$ & $-0.071^{\star \star}$ \\
\hline Wind velocity, $\mathrm{m} / \mathrm{s}$ & $0.059^{*}$ & 0.052 & $0.069^{* *}$ & $0.097^{* *}$ & $0.049^{*}$ \\
\hline Wind max velocity, $\mathrm{m} / \mathrm{s}$ & -0.008 & -0.051 & 0.013 & 0.053 & -0.011 \\
\hline Min tem, ${ }^{\circ} \mathrm{C}$ & $-0.085^{\star \star}$ & $-0.104^{* *}$ & 0.031 & -0.042 & $-0.061^{\star *}$ \\
\hline Max tem, ${ }^{\circ} \mathrm{C}$ & $-0.105^{\star *}$ & $-0.121^{\star *}$ & 0.021 & $-0.126^{\star *}$ & $-0.080^{* *}$ \\
\hline Humidity, \% & -0.027 & 0.026 & -0.024 & -0.064 & -0.016 \\
\hline $\mathrm{SO}_{2}, \mathrm{mg} / \mathrm{m}^{3}$ & $0.077^{\star *}$ & 0.058 & -0.023 & 0.058 & $0.066^{* *}$ \\
\hline $\mathrm{NO}_{2}, \mathrm{mg} / \mathrm{m}^{3}$ & $0.111^{* *}$ & $0.149^{* *}$ & $0.071^{\star *}$ & $0.119^{* *}$ & $0.123^{* *}$ \\
\hline $\mathrm{PM} 10 \mu \mathrm{g} / \mathrm{m}^{3}$ & $0.104^{\star *}$ & $0.202^{\star *}$ & $0.050^{*}$ & $0.196^{\star *}$ & $0.124^{\star *}$ \\
\hline PM2.5 $\mu \mathrm{g} / \mathrm{m}^{3}$ & 0.046 & $0.124^{\star *}$ & -0.011 & $0.075^{\star}$ & $0.063^{\star *}$ \\
\hline $\mathrm{CO}, \mathrm{mg} / \mathrm{m}^{3}$ & 0.013 & -0.020 & -0.020 & -0.016 & $0.042^{*}$ \\
\hline $\mathrm{O}_{3}, \mathrm{mg} / \mathrm{m}^{3}$ & $-0.120^{\star *}$ & $-0.295^{\star *}$ & $-0.124^{\star *}$ & $-0.144^{\star \star}$ & $-0.153^{\star *}$ \\
\hline
\end{tabular}

Correlation is significant at the 0.01 level (2-tailed). ${ }^{*}$ Correlation is significant at the 0.05 level (2-tailed).*

Table 4. Summary of cardiovascular system disease admission in relative risk (RR) and $95 \%$ confidence interval for $10 \mu \mathrm{g} / \mathrm{m}^{3}$ $\left(\mathrm{mg} / \mathrm{m}^{3}\right)$ change in concentration of pollutants at mean lag $0-3$, significance with temperature and wind velocity adjusted in all age.

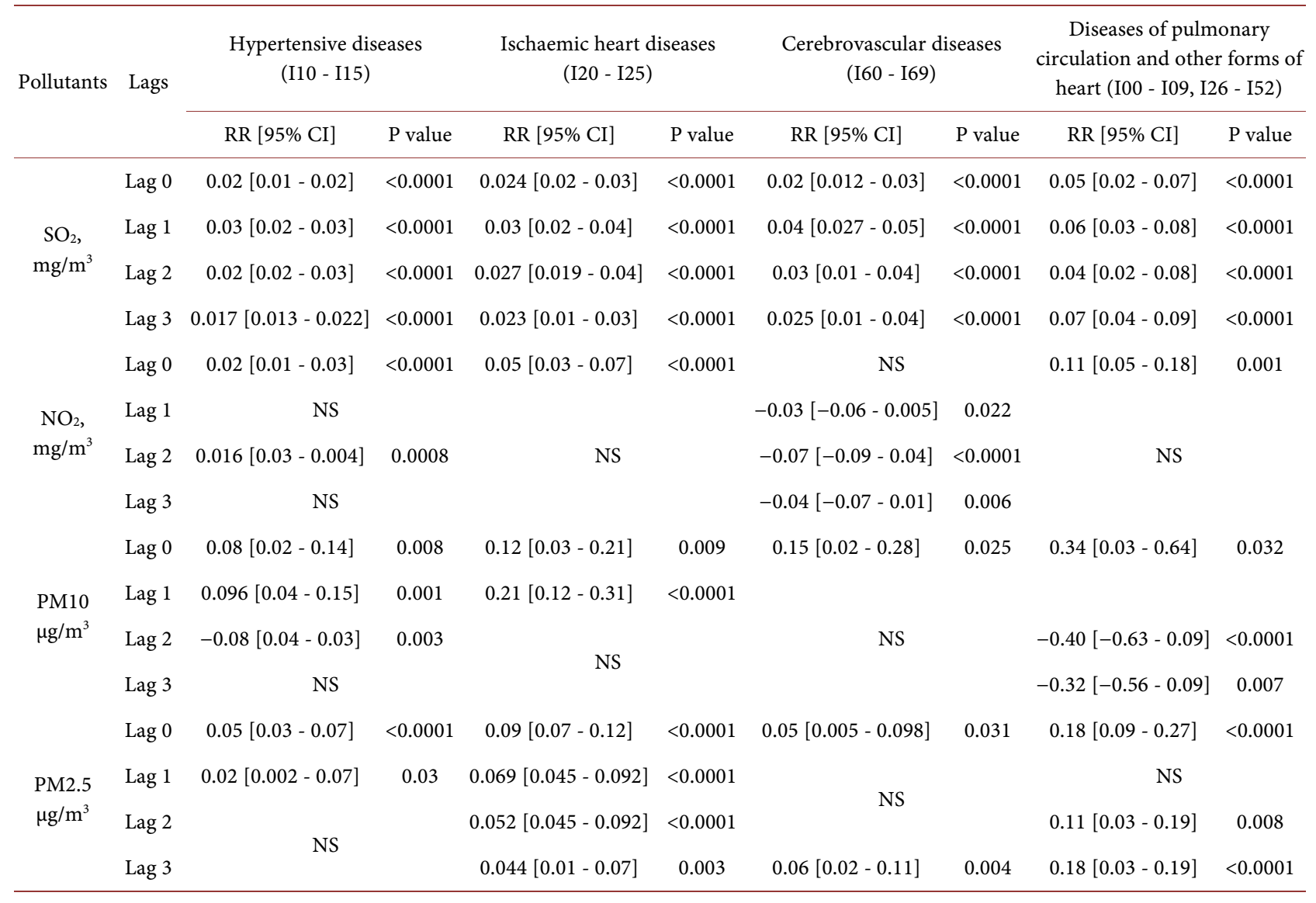




\section{Continued}

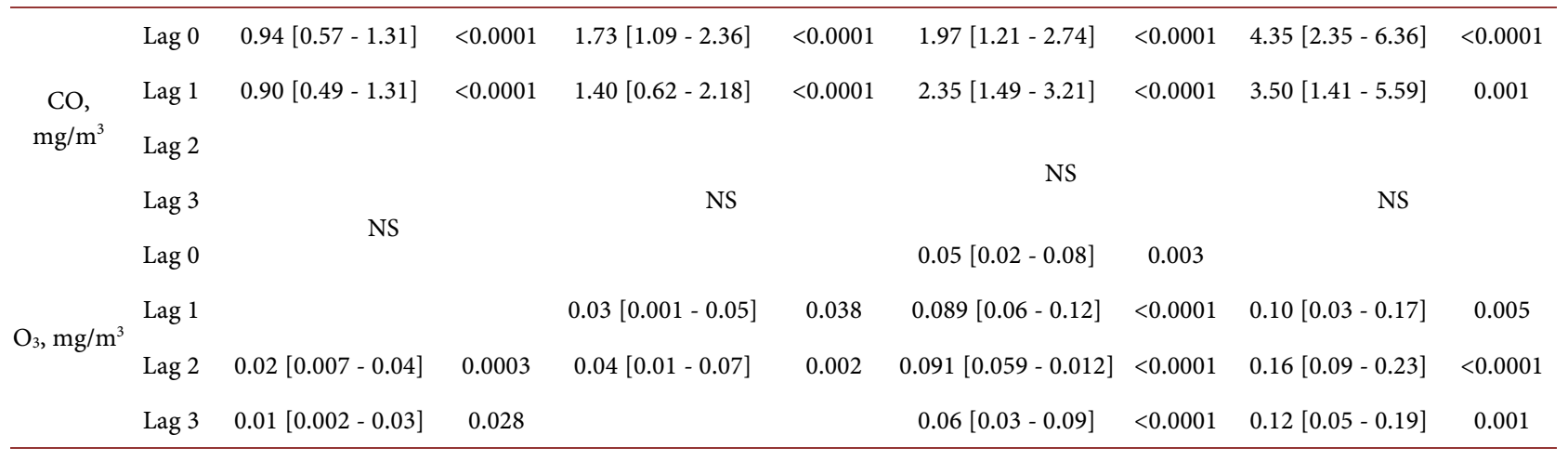

Table 5. Summary of hospital admission of cardiovascular system disease in relative risk (RR) and $95 \%$ confidence interval for $10 \mu \mathrm{g} / \mathrm{m}^{3}\left(\mathrm{mg} / \mathrm{m}^{3}\right)$ change in concentration of pollutants at mean lag $0-3$, significance with temperature and wind velocity adjusted by season.

\begin{tabular}{|c|c|c|c|c|c|}
\hline \multirow[t]{2}{*}{ Pollutant } & \multirow[t]{2}{*}{ Lags } & \multicolumn{2}{|c|}{$\begin{array}{c}\text { Cardiovascular system } \\
\text { disease admission cold season }\end{array}$} & \multicolumn{2}{|c|}{$\begin{array}{l}\text { Cardiovascular system disease } \\
\text { admission warm season }\end{array}$} \\
\hline & & $\mathrm{RR}[95 \% \mathrm{CI}]$ & $P$ value & $\mathrm{RR}[95 \% \mathrm{CI}]$ & $P$ value \\
\hline \multirow{4}{*}{$\mathrm{SO}_{2}, \mathrm{mg} / \mathrm{m}^{3}$} & Lag 0 & $0.05[0.04-0.06]$ & $<0.0001$ & \multirow{4}{*}{ NS } & \\
\hline & Lag 1 & $0.06[0.05-0.07]$ & $<0.0001$ & & \\
\hline & $\operatorname{Lag} 2$ & $0.05[0.04-0.06]$ & $<0.0001$ & & \\
\hline & Lag 3 & $0.01[0.0001-0.02]$ & 0.02 & & \\
\hline \multirow{4}{*}{$\mathrm{NO}_{2}, \mathrm{mg} / \mathrm{m}^{3}$} & Lag 0 & \multirow{4}{*}{ NS } & & \multirow{4}{*}{ NS } & \\
\hline & Lag 1 & & & & \\
\hline & Lag 2 & & & & \\
\hline & Lag 3 & & & & \\
\hline \multirow{4}{*}{$\mathrm{PM} 10 \mu \mathrm{g} / \mathrm{m}^{3}$} & Lag 0 & $0.31[0.22-0.41]$ & $<0.0001$ & \multirow{4}{*}{ NS } & \\
\hline & Lag 1 & $0.29[0.19-0.38]$ & $<0.0001$ & & \\
\hline & Lag 2 & $0.27[0.15-0.38]$ & $<0.0001$ & & \\
\hline & Lag 3 & $0.13[0.01-19]$ & $<0.0001$ & & \\
\hline \multirow{4}{*}{$\mathrm{PM} 2.5 \mu \mathrm{g} / \mathrm{m}^{3}$} & Lag 0 & $0.28[0.23-0.23]$ & $<0.0001$ & & \\
\hline & Lag 1 & $0.23[0.19-0.27]$ & $<0.0001$ & $0.06[0.23-0.35]$ & $<0.0001$ \\
\hline & Lag 2 & $0.18[0.14-0.23]$ & $<0.0001$ & \multirow{2}{*}{ NS } & \\
\hline & Lag 3 & $0.05[0.02-0.08]$ & $<0.0001$ & & \\
\hline \multirow{4}{*}{$\mathrm{CO}, \mathrm{mg} / \mathrm{m}^{3}$} & Lag 0 & $2.95[2.41-3.49]$ & $<0.0001$ & $0.37[0.13-0.62]$ & $<0.0001$ \\
\hline & Lag 1 & $3.25[2.73-3.77]$ & $<0.0001$ & $0.39[-0.63-0.14]$ & $<0.0001$ \\
\hline & Lag 2 & $2.43[1.98-2.98]$ & $<0.0001$ & \multirow{3}{*}{ NS } & \\
\hline & Lag 3 & $1.19[0.84-1.53]$ & $<0.0001$ & & \\
\hline \multirow{4}{*}{$\mathrm{O}_{3}, \mathrm{mg} / \mathrm{m}^{3}$} & Lag 0 & $0.02[0.01-0.04]$ & $<0.0001$ & & \\
\hline & Lag 1 & $0.04[0.03-0.06]$ & $<0.0001$ & $0.03[0.01-0.05]$ & 0.01 \\
\hline & $\operatorname{Lag} 2$ & $0.02[0.01-0.03]$ & $<0.0001$ & \multirow{2}{*}{ NS } & \\
\hline & Lag 3 & $0.04[0.03-0.06]$ & $<0.0001$ & & \\
\hline
\end{tabular}


Other sources include traffic, dust suspension, and open burning of waste and the brick industry. In addition to being a large source of ambient air pollution, polluting fuels such as raw coal and biomass use for cooking and heating contribute to a significant additional burden to the health of the population from household air pollution.

Almost a third of the population of Mongolia is children and 69 percent of the population lived in urban areas. As a consequence of drastic urban migration, Ulaanbaatar is facing significant environmental and developmental challenges since the 1990s [10]. In 2010, the average daily concentration of nitrogen in the air in Ulaanbaatar has more than doubled since 2007 and the average daily concentration of sulfur dioxide has almost trebled. Findings of the survey by Enhjargal A. et al. [11] show the percentage of combined effects on respiratory diseases in the winter season is $\mathbf{5 2 . 9}$ for average temperature, humidity, nitrogen dioxide, and PM10; the percentage of combined effects on cardiovascular diseases in the winter season is 37.2 for average temperature, humidity, nitrogen dioxide, and PM10; the percentage in the autumn is 5.4 for PM10 only, and the percentage in the summertime is 17.4 for wind speed and average temperature, while in the autumn the percentage of combined effects of sulfur dioxide, nitrogen dioxide, and PM10 is 25.4 .

A recent study verifies that cardiovascular diseases are caused by air pollution. For instance, scientists Dockery and Pope from the Harvard University of USA discovered that by reducing the content of $\mathrm{PM}_{10}$ in the air (until the standard rate) the death caused by cardiovascular diseases can be reduced by 15 percent [12] [13] [14].

Daily cardiovascular system disease admissions were found to be directly correlated with the daily level of all air pollutants. Cardiovascular health effects are more associated with particulate pollutant rather than gaseous pollutants which were similar to Wong et al. (2002). They concluded that for respiratory admissions ( $\geq 65$ years of age), significant positive associations were observed with particulate matter $<10 \mu \mathrm{m}$ in aerodynamic diameter (PM10), nitrogen dioxide, sulfur dioxide, and ozone in both cities. These associations tended to be stronger at shorter lags in Hong Kong and at longer lags in London. Associations were stronger in cool season in Hong Kong and in the warm season in London, periods during which levels of humidity are at their lowest in each city. For cardiac admissions (all ages) in both cities, significant positive associations were observed for $\mathrm{PM} 10, \mathrm{NO}_{2}$, and $\mathrm{SO}_{2}$ with similar lag patterns [15]. A similar tendency also observed in this survey.

To evaluate the lag effect in detail, we computed 24-h means starting from various times: the 0 -h lag starts from 00:00 hours on a corresponding day, the 6-h lag starts from 18:00 hours on the previous day, and the 12-h lag starts from 12:00 hours on the previous day, etc., and they last for $24 \mathrm{~h}$. The 6-, 12-, 18-, 72-h, 96-h lags were calculated and used to get the estimated effects. The 0-h lag is the pollutant value on the same day, the 24 -h lag is the 1-day lag value, the 
48-h lag is the 2-day lag value, etc. In order to allow for different lag structures for different causes of disease, the traditional method, and the linear regression analysis were supplied for model comparison. For total disease admission, the estimated effect of lag 0 was the highest and can conclude that on the same day the effect of all pollutants level was affected. Similar same day effect also observed but next day's effects were significant only at the fists day of each cardiovascular disease admission.

Our result was also similar with Peters et al. (2000) which were reported that defibrillator discharges in patients with implanted cardioverter defibrillators did not follow exposure to the particulate matter immediately but required an induction time of 1 or 2 days. Cardiovascular disease was more affected by exposure on the previous day [16]. Our study shows similar results for the cardiovascular system disease admission. However, Braga et al. (2001) reported that cardiovascular deaths represented an acute response to exposure to air pollution, but respiratory deaths were more affected by exposure on the 1 or 2 previous days [17]. In our survey the cardiovascular disease admission, the highest effect of exposure to air pollution (PM2.5 and PM10 level) was observed at the first and second days of exposure. Also, we found the PM10 exposure level was significantly higher than the PM2.5 level.

Many researchers had different results it could be different for many reasons. Actually, the mixture of particles is likely to vary with the study areas in the distribution of size, number, and chemical composition. The toxicity of particulate matter depends on its chemical composition and size distribution. Fine particles (PM2.5) have been found to have bigger effects on health than PM10 [18]. The PM2.5 fraction in PM10 is likely to be different in different geographical regions. A further reason is that different populations have different structures. Some studies reported different susceptibilities for different groups (especially infants and the elderly) [14] [15]. In our survey, for chronic cardiovascular disease admission, the highest effect of exposure to air pollution (PM2.5 and PM10 level) was observed at the second and fourth days of exposure. PM2.5 exposure to cardiovascular system disease admission was significantly higher than the PM10 level. There are also gaseous pollutants higher effects were observed for all lags of them, especially during the cold period of time. It could be explained that the origins of the pollutants in Ulaanbaatar basically come from soil and dust.

According to the survey of the World Bank carried out a survey in Ulaanbaatar in 2011, PM2.5 and PM10 in the air of Ulaanbaatar had a constant and strong correlation with a cardiovascular disease caused hospitalization. For PM2.5, every $10 \mu \mathrm{g} / \mathrm{m}^{3}$ growth of the pollutant led to a $0.8 \%$ increase in the cardiovascular disease caused hospitalization. For this survey, it was $0.31 \%$ during the cold season [5].

The associations between air pollution and cardiovascular morbidity have been well established by many researchers throughout the world ever since the fateful incident of the London Fog of 1952 [3]. Thus, as expected this study 
demonstrated significant correlations between cardiovascular morbidity with $\mathrm{PM}$ 2.5, $\mathrm{PM} 10, \mathrm{NO}_{2}, \mathrm{SO}_{2}, \mathrm{CO}, \mathrm{O}_{3}$, and some meteorological parameters.

The correlation mainly between cardiovascular disease case admissions with meteorological parameters is because the cold winter conditions in Ulaanbaatar result in the accumulation of pollutants in the atmosphere. Thus, population exposure to air pollution is increasing significantly during the winter months.

\section{Conflicts of Interest}

The authors declare no conflicts of interest regarding the publication of this paper.

\section{References}

[1] Tsegmed, Ts. (1969) Physical Geography of Mongolia, Ulaanbaatar.

[2] NSO (2019) Air Pollution and Health. UB Statistics Department, Ulaanbaatar.

[3] Godish, T. (2004) Air Quality. 4th Edition, Lewis Publishers, Boca Raton.

[4] Lodoysamba, S., Guttikunda, S.K., Bulgansaikhan, B. and Dashdondog, B. (2013) Particulate Pollution in Ulaanbaatar, Mongolia. Air Quality, Atmosphere, and Health, 6, 589-601. https://doi.org/10.1007/s11869-013-0198-7

[5] WB (2011) Air Monitoring and Health Impact Baseline Study. Ulaanbaatar.

[6] MOET (2016) Emission Inventory Report, 2014. BCI Publishing, Ulaanbaatar.

[7] Spickett, J., Baker, A., Burma, B., Enkhtsetseg, Sh., et al. (2002) Preliminary Health Risk Assessment of Environmental Pollution in Ulaanbaatar City, Mongolia. World Health Organization, Ministry of Health, and Public Health Institute, Ulaanbaatar.

[8] Burmaa, B. and Enkhtsetseg, Sh. (1996) Results of the Study on the Correlation between Morbidity among the Population and the Children of Ulaanbaatar and Air Pollution. Healthy City Wonderful Life, Ulaanbaatar.

[9] Huang, Y.-K., Luvsan, M.-E., et al. (2013) Land Use Patterns and $\mathrm{SO}_{2}$ and $\mathrm{NO}_{2}$ Pollution in Ulaanbaatar, Mongolia. Environmental Research, 124, 1-6. https://doi.org/10.1016/j.envres.2013.02.006

[10] NSO (2013) The 5th MDG Progress Report the Total Population at 2.9 Million of Which 1.2 Million Reside in the Capital. Ulaanbaatar.

[11] Altangerel, E., Burmaajav, B. and Batbaatar, S. (2014) Health Impact Assessment of Ambient air PM10 and PM2.5 on Acute and Chronic RSD and CVD in Ulaanbaatar City. Health Sciences, 11, 49-53.

[12] Dockery, D.W. and Pope, C.A. (1994) Acute Respiratory Effects of Particulate Air Pollution. Annual Review of Public Health, 15, 107-132. https://doi.org/10.1146/annurev.pu.15.050194.000543

[13] Pope III, Burnett, R.T., Thun, M.J., Calle, E.E., Krewski, D., Ito, K. And Thurston, G.D. (2002) Lung Cancer, Cardiopulmonary Mortality, and Long-Term Exposure to Fine Particulate Air Pollution. J Am Med Assoc, 287, 1132-1141.

[14] Pope, C.A., Burnett, R.T., Thun, M.J., Calle, E.E., Krewski, D., Ito, K. and Thurston, G.D. (2002) Lung Cancer, Cardiopulmonary Mortality, and Long-Term Exposure to Fine Particulate Air Pollution. Journal of the American Medical Association, 287, 1132-1141. https://doi.org/10.1001/jama.287.9.1132

[15] Wong, C., Atkinson, R.W., et al. (2002) A Tale of Two Cities: Effects of Air Pollution on Hospital Admissions in Hong Kong and London Compared. Environmental 
Health Perspectives, 110, 67-77. https://doi.org/10.1289/ehp.0211067

[16] Peters, A., et al. (2000) Air Pollution and Incidence of Cardiac Arrhythmia. Epidemiology, 11, 11-17. https://doi.org/10.1097/00001648-200001000-00005

[17] Braga, A., Zanobetti, A. and Schwartz, J. (2001) Structure between Particulate Air Pollution and Respiratory and Cardiovascular Deaths in 10 US Cities. Journal of Occupational and Environmental Medicine, 43, 927-933. https://doi.org/10.1097/00043764-200111000-00001

[18] Bremner, S.A., Anderson, H.R., Atkinson, R.W., McMichael, A.J., Strachan, D.P., Bland, J.M., et al. (1999) Short Term Associations between Outdoor Air Pollution and Mortality in London 1992-4. Occupational and Environmental Medicine, 56, 237-244. https://doi.org/10.1136/oem.56.4.237 